\title{
DEMOKRASI DAN PENEGAKAN HUKUM DALAM WAWASAN AL-QUR'AN
}

\author{
Muhammad Soleh Ritonga* \\ Universitas Indraprasta PGRI Jakarta, Kampus A Jl. Nangka No.58C Tanjung Barat (TB \\ Simatupang), Jagakarsa, Jakarta Selatan 12530. Kampus B Jl. Raya Tengah No. 8o, Kel. \\ Gedong, Kec. Pasar Rebo, Jakarta Timur 1376o \\ E-mail: * muhammadsolehrtg@gmail.com
}

No. Tlp/WA: o81298408623

Diterima: 8 September 2021; Diperbaiki: 20 September 2021; Disetujui: 28 September 2021

\begin{abstract}
Islam is a religion that regulates people's lives. This includes democracy and law enforcement. In democracy there are several views of Muslim experts, some accept but on the condition that the power is not absolute in the hands of the people, and there are also those who reject it altogether. In the ulama democracy accepted in Islam is deliberation and consensus in matters that are in accordance with religious rules. In Islamic democracy, it is very radicalism. This can be seen from the views of some scholars of Tafsir regarding Surah Al-Baqarah verse 143 that Islam is not exceeding the limit. Meanwhile, good law enforcement can be created because of a well-executed democracy. In Islam, law enforcement is a profession that is not easy. There are criteria and ethics for judges as law enforcers so that the law can produce a fair law. In the enforcement of the law must glorify God's commandments and have a sense of compassion or concern and a deep sense of justice that is shown. Democracy and law enforcement in the perspective of the Qur'an there are ethics that must be done, so that democracy and law enforcement cannot be separated from religion as secular views separate religion from worldly problems. Religion with the guidance of the holy book Al-Qur'an plays an important role in guiding democracy and good law enforcement.
\end{abstract}

Keywords; Deliberation, consensus, moderate, fair

\begin{abstract}
Abstrak.
Islam adalah agama yang mengatur kehidupan dibergai bidang. Termasuk dalam demokrasi dan penegakan hukum. Dalam hal demokrasi terdapat beberapa pandangan para ahli muslim ada yang menerima tapi dengan syarat tidak mutlak kekuasaan di tangan rakyat, ada juga yang menolak sama sekali. Dalam penafsiran ulama demokrasi yang diterima dalam Islam adalah musyawarah kemufakatan dalam hal yang sesuai aturan agama. Dalam demokrasi Islam sangat menentang dengan radikalisme. Hal ini dapat dilihat dari pandangan beberapa ulama ahli Tafsir tentang surat Al-Baqarah ayat 143 bahwa Islam adalah moderat tidak melampaui batas. Sedangkan penegakan hukum yang baik itu bisa tercipta karena demokrasi yang dijalankan dengan baik. Dalam Islam para penegak hukum adalah profesi yang tidak mudah ada kriteria dan etika bagi hakim sebagai penegak hukum supaya hukum bisa menghasilkan hukum yang adil. Dalam pnegakan hukum tersebut haruslah mengagungkan peintah Allah dan mempunyai rasa welas asih atau prihatin dan rasa mendalam yang ditunjukkan dengan berlaku adil. Demokrasi dan Penegakan hukum dalam wawasan Al-Qur'an ada etika yang harus dilakukan, sehingga demokrasi dan penegakan hukum tidak bisa dipisahkan dari agama sebagaimana pandangan sekuler yang memisahkan agama dengan masalah keduniawian. Agamalah dengan panduan kitab suci Al-Qur'an berperan penting dalam memandu demokrasi dan penegakan hukum yang baik.
\end{abstract}


Kata kunci; Musyawarah, mufakat,moderat, adil.

Tautan permanen/DOI: $\mathrm{xxx}$

\section{Pendahuluan}

Demokrasi dalam pandangan para tokoh Islam ada yang menyatakan bahwa menolak sama sekali demokrasi, namun ada juga demokrasi bisa diterima dengan syarat tertentu. ${ }^{1}$ dalam hal ini demokrasi harus di atur oleh agama.

Berbeda dengan pandangan sekuler bahwa agama tidak boleh mengatur keduniaian termsuk masalah politik, seperti demokrasi dan penegakan hukum dan lain-lainnya. ${ }^{2}$

Dari latar belakang ini, penulis tertarik untuk meneliti bagaimana pandangan Islam terhadap demokrasi dan penegakan hukum? Dalam hal ini sesuai dengan kitab suci Al-Qur'an, maka penelitian demokrasi dan penegakan hukum ini diteliti dengan berwawasan Al-Qur'an.

Dalam tinjuan pustaka sebelumnya, bahwa peniliti sudah ada yang meneliti tentang demokrasi dan penegakan hukum di beberapa jurnal, seperti Demokrasi dalam Pandangan Islam dan Barat yang ditulis oleh Afifa Rangkti, penelitian ini hanya fokus pada perbedaan antara demokrasi Islam dengan Barat. ${ }^{3}$

Artikel lainnya adalah tulisan Farida Nur 'Afifah tentang Demokrasi dalam Al-Qur'an:Implementasi Demokrasi di Indonesia, yang hasil penelitiannya mengungkap demokrasi yang diimplementasikan di Indonesia.

\footnotetext{
${ }^{1}$ Afifa Rangkuti (2018). Demokrasi dalam Pandangan Islam dan Barat, dalam Jurnal Ilmiah Penegakan Hukum, 5 (2): 49-59.

${ }^{2}$ Fazlur Rahman (1405/1985). Islam dan Modrenitas. Bandung: Pustaka: 54.

${ }^{3}$ Afifa Rangkuti (2018). ..... 5 (2): 49-59

Page | 110
}

Hanya satu cara yang paling tepat dengan Islam dalam melaksanakan demokrasi, yaitu harus melalui prinsipprinsip yang diatur dalam al-Qur'an. Dengan cara ini maka demokrasi akan memanifestasikan nilai-nilai

Ilahi pada semua aspek kehidupan, dengan perumpamaan apa yang telah dimplementasikan nabi Muhammad pada masyarakat Madinah yang termuat pada peraturan piagam Madinah. ${ }^{4}$

Penelitian lainnya adalah Eva Iryani dengan judul Hukum Islam, Demokrasi dan Hak Asasi Manusia. Hasil kajiannnya adalah Demokrasi dan HAM diatur dalam Al-Qur'an. Islam memiliki landasan hukum yang kuat, Al-Quran salah satunya. Demokrasi sering didefinisikan sebagai penghormatan terhadap hak asasi manusia, partisipasi dalam pengambilan keputusan dan persamaan di depan hukum. Sejak saat itu muncul idiom demokrasi, sebagai egalite (persamaan), persamaan (justice), kebebasan (freedom), hak asasi manusia (human rights), dan segera. Hak Asasi Manusia telah ditetapkan dalam AlQur'an. juga diatur dalam hukum di setiap negara. dijalankan dengan aturan yang ada. ${ }^{5}$

Penelitian lainnya adalah Penegakan Hukum atas Keadilan dalam Pandangan Islam, olehM. Rais Ahmad. Hasil kajiannya adalah untuk memperoleh hukum dengan adil,

\footnotetext{
${ }^{4}$ Farida Nur 'Afifah (2020). Demokrasi dalam Al-Qur'an:Implementasi Demokrasi di Indonesia dalam Jurnal Kaca Jurusan Ushuluddin STAI AL FITHRAH. 10 (1): 6-32.

5 Eva Iryani Hukum Islam. (2017). Demokrasi dan Hak Asasi Manusia dalam Jurnal Ilmiah Universitas Batanghari Jambi. 17 (2): 24-31.
} 
ditentukan oleh faktor manusia. Keadilan sosial akan tercipta bila pemerintah menegakkan keadilan hukum yang adil, ada rasa saling tolongmenolong dan interdependensi (adanya ketergantungan sesama), bukan dengan kezaliman hukum yang diterapkan. ${ }^{6 \mathrm{i}}$

Tujuan Penelitian ini adalah untuk mendapatkan wawasan Al-Qur'an tentang Demokrasi dan Penegakan Hukum. Dan menjadi bantahan bagi pandangan sekuler yang menyatakan bahwa agama tidak boleh mengatur atau mencampuri urusan demokrasi dan penegakan hukum.

\section{Metode}

Metode pengumpulan data pada penyusunan artikel ini, menggunakan corak Library, murni Library Research, merupakan metode riset kepustakaan, sedangkan pendekatannya menggunakan pendekatan kualitatif. Untuk sumber utamanya adalah AlQur'an, Hadits, Tafsir. Sedangkan sumber sekundernya adalah buku-buku dan jurnal-jurnal serta beberapa website yang ada hubungannya dengan bahasan pada artikel ini.

\section{Hasil dan Pembahasan Penelitian}

\section{A. Pengertian Demokrasi}

Demokrasi adalah kata yang sudah mendunia termasuk sudah dipakai dalam bahasa Indonesia. Namun sebetulnya kata demokrasi bukanlah asli dari bahasa Indonesia. Menurut Prof. Sukron Kamil, beliau mengutip pendapat Peter Jhones, yang menyatakan bahwa kata demokrasi berasal dari bahasa Yunani, yang terdiri

${ }^{6}$ M. Rais Ahmad (2013). Penegakan Hukum atas Keadilan dalam Pandangan Islam dalam Jurnal Mizan; Jurnal Ilmu Syariah, FAI Universitas Ibn Khaldun (UIKA) BOGOR. 1 (2): 143-148. dari dua kata yang digabung, yaitu kata demos dan kratos, mengandung arti kekuasaan oleh rakyat. Demokrasi adalah suatu sistem politik yang memberikan perlakuan yang sama terhadap orang lain pada segi politik, mempunyai kedaulatan yang sama, baik itu dipilih secara langsung atau tidak langsung dengan perwakilan yang dipilih lewat pemilu secara bebas untuk sarana kontrol yang efektif. ${ }^{7 i}$ Dalam dunia barat kekuasaan mutlak di tangan rakyat. Hal ini senada dengan pendapat sekuler.

Pada kehidupan masyarakat, sekularisasi berupaya untuk menghilangkankan peran-peran dari keagamaan. Masyarakat akan menjadi menjadi sekular disebabkan agama sudah, sebuah ketika agama sudah tersingkirkan dalam kehidupan. Sekularisme merupakan kepercayaan bahwa peroblematika dalam kehidupan sosial kemasyarakatan harus bersis dan tidak ada ikut campur dari semua aturan dogma dan agama. ${ }^{8}$

Secara global sekularisme merupakan paham yang menyatakan agama tidak berhubungan dengan problematika keduniaan yaitu persoalan sosial budaya maupun politik. Agama hanya digunakan pada ritual keagamaan saja. Tingkah laku dan etika tidak bersumber dari agama tapi diambil dari sumber kesejahteraan sosial dan kehidupan sekarang. ${ }^{9}$

Dalam pandangan sekuler demokrasi tidak boleh diatur oleh agama. Agama tidak punya otoritas

\footnotetext{
${ }^{7}$ Sukron Kami (2013) Pemikiran Poiitik Islam Tematik, Jakarta: Kencana Prenada Media Grouop, cet 1: 85 .

${ }^{8}$ Ilyas Bayunus dan Farit Ahmad. (1996). Sosiologi Islam Dan Masyarakat Kontemporer. Bandung: Mizan: 54.

${ }^{9}$ Harun Nasution. (1975). Pembaharuan Dalam Islam Sejarah Pemikiran Dan Gerakan. Jakrta: Bulan Bintang: 131.
} 
dalam membangun politik yang termsuk dalam masalah demokrasi dan penegakan hukum.

Dalam pandangan tokoh Islam, menentang pendapat sekuler tersebut seperti padangat Al-Maududii. Menurut Al-Maududi, beliau menolak dengan tegas akan demokrasi ala barat. Menurutnya, demokrasi itu memberikan kekuasaan sebesar-besarnya kepada rakyat dan tidak dikenal dalam Islam, demokrasi cendrung sekuler yang merupakan hasll buatan manusia sekaligus merupakan pertentangan Barat terhadap agama. Al-Maududi memperkenalkan istilah demokrasi Islami yang disebut dengan theodemokracy merupakan pemerintahan yang menggunakan sistem demokrasi dengan berlandaskan pada ilahiyah, sistem demokrasi pada pemerintahan ini rakyat diberi kedaulatan tidak mutlak, kedaulatannya terbatas, harus mengikuti aturan agama. ${ }^{10}$ dan Maududi, 1996:130)

Begitu juga pendapat Muhammad Imarah, Islam tidak menerima demokrasi secara mutlak dan juga tidak menolaknya secara mutlak. Dalam demokrasi barat secara mutlak berada di tangan rakyat. Sementara dalam Islam memakai sistem syura kekuasaan adalah milik Allah, sebagai pemegang kekuasaan tertinggi. Manusia hanyalah menjabarkan dan merumuskan hukum sesuai dengan prinsip yang sudah digariskan oleh Allah. Dan untuk hal yang tidak diatur oleh Allah maka yang dilakukan adalah mengadakan ijtihad. ${ }^{11}$

Pendapat dari kedua tokoh tersebut di atas bersesuaian dengan $\mathrm{Al}-$ Qur'an. Hal tersebut dapat kita lihat pada surat Ali Imran ayat 159 yang

10 Al-Maududiy, Abu al-A'la. (1977). Mabdi'u al-Islam. Damaskus: Dar al-Qur'an alKarim: 130

${ }^{11}$ Afifa Rangkuti (2018). ..... 5 (2): 49-59

Page | 112 memerintahkan musyawarah untuk etika dalam berdemokrasi, sebagaimana firman Allah:

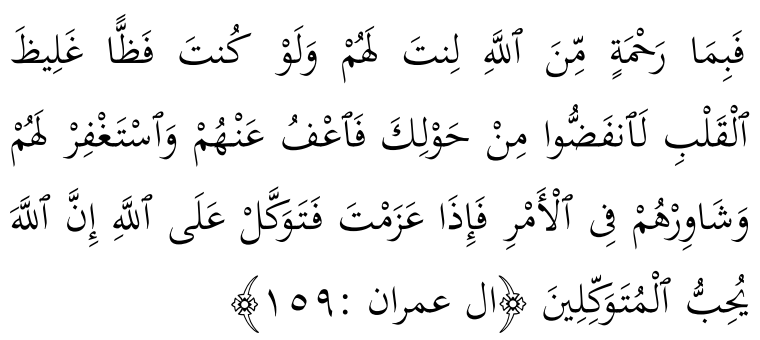

"Maka berkat rahmat Allah engkau (Muhammad) berlaku lemah lembut terhadap mereka. Sekiranya engkau bersikap keras dan berhati kasar, tentulah mereka menjauhkan diri dari sekitarmu. Karena itu maafkanlah mereka dan mohonkanlah ampunan untuk mereka, dan bermusyawarahlah dengan mereka dalam urusan itu. Kemudian, apabila engkau telah membulatkan tekad, maka bertawakallah kepada Allah. Sungguh, Allah mencintai orang yang bertawakal".(QS. Ali Imran [3] : 159)

Selama Rasulullah hidup beliau
sering musyawarah dengan sahabat-sahabat beliau dalam urusan kenegaraan datau kemasyarakatan yang perlu menjadi perhatian bersama. ${ }^{12}$

Di masa Rasulullah majelismajelis perwakilan seperti yang ada di negara-negara sekarang ini belum diatur dan mempunyai anggota tertentu dan terbatas, bersidang pada waktu tertentu dan mempunyai peraturan-peraturan yang lengkap. Agama Islam itu bersifat universal untuk segala bangsa, maka perlu disesuaikan dengan tiap-tiap tempat dan diselaraskan dengan segala masa. Sedangkan keadaan masyarakat

${ }^{12}$ Muhammad 'Alî al-Shâbûnî (1420 H/ 1999 M). Shafwah al-Tafâsîr, Jakarta: Dâr al-Kutub al-Islâmiyah, cet 1, jilid 1: 240.

Muhammad Soleh Ritonga 
dan pergaulan di suatu tempat atau di sauatu masa sering berbeda dari tempattempat atau masa-masa yang lain. Maka kalau baginda nabi Muhammad menetapkan peraturan yang sesuai dengan masa dan tempat beliau saat itu, beliau tidak terlepas dari kekhawatiran, kalau di kemudian hari umat beliau menyangka peraturan itu mesti begitu, tidak boleh diubah lagi walaupun tidak sesuai dengan keadaan tempat masa itu, menutup mata, mengikuti susunan dan peraturan yang ada saja, tidak memperhatikan tujuan dan manfaat dari permusyawarah itu disediakan. Karena itu, baginda Nabi menyerahkan teknis dan format permusyawarahan itu pada kebijakan umat yang sesuai dengan masyarakat di tempat dan masa mereka, selaras dengan keadaan dan kemaslahatan mereka di waktu itu. ${ }^{13}$

Kesepakatan musyawarah tersebut adalah kesepakan yang baik, tidak melanggar aturan agama,tidak boleh melakukan kesepakatan yang buruk, sebagaimana firman Allah:

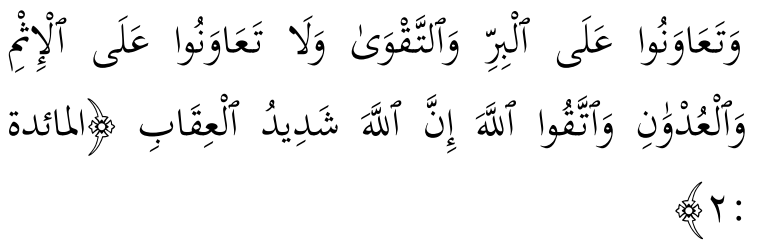

“... Dan tolong-menolonglah kamu dalam (mengerjakan) kebajikan dan takwa, dan jangan tolong-menolong dalam berbuat dosa dan permusuhan. Bertakwalah kepada Allah, sungguh, Allah sangat berat siksaan-Nya." (QS. Al-Maidah[5] : 2)

Prinsip tolong menolong harus pada hal yang ditetapkan Allah akan kebolehan dalam mengerjakannya, ada rasa takut kepada Allah bersekongkol dalam melakukan apa yang Allah larang, tidak mengadakan persekutuan

\footnotetext{
${ }^{13}$ Sulaiman Rasjid, H.(2005). Fiqh Islam, Bandung: Sinar Baru Algensindo, cet 37: 504.
}

permukatan dalam hal kemaksiatan dan persekutuan permukatan dalam hal menolak hukum-hukum yang sudah ditetapkan Allah. ${ }^{14}$

\section{B. Radikalisme}

Dalam KBBI radikal mempunyai arti secara menyeluruh, habis-habisan, perubahan yang menyeluruh, 2. Dalam politik amat keras menuntut perubahan (undangundang, pemerintahan dan sebagainya, 3. Dalam politik, maju dalam berpikir dan bertindak. Sedangkan radikalisme adalah paham yang menganut cara radikal dalam politik. $^{15}$

Menurut Kepala Humas dan Pusat Informasi BNPT Irfan Idris mengatakan setidaknya ada empat hal ciri radikalisme. Kriteria ini kemudian yang dipakai BNPT untuk memblokir situs Islam yang mengancam Negara Kesatuan Republik Indonesia (NKRI). Kriteria pertama, yakni radikalisme bisa ditimbulkan dari ingin melakukan perubahan dengan cepat menggunakan kekerasan mengatasnamakan agama. Kedua, mengkafirkan orang lain. Ketiga, mendukung, menyebarkan dan mengajak bergabung dengan ISIS. Terakhir, memaknai jihad secara terbatas. ${ }^{16}$

${ }^{14}$ Jalâl al-Dîn Muhammad ibn Ahmad AlMahallî dan Jalâl al-Dîn Abd al-Rahmân ibn Abî Bakr al-Suyûthî (t.t). Tafsîr al-Jalâlain, Qâhirah: Dâr al-Hadîts: 134.

15 Tim Penyusun Kamus Departemen Pendidikan dan Kebudayaan. (2008). Kamus Besar Bahasa Indonesia, Jakarta: Balai Pustaka, .cet. 16: 1151-1152.

${ }^{16}$ Irfan Idris.(15 Agustus 2019). Ini Kriteria Radikalisme Menurut BNPT sourches URL https://www.republika.co.id/berita/nasional/umum/1 5/03/31/nm2pur-ini-kriteria-radikalisme-menurutbnpt.

Page | 113 
Istilah radikalisme menurut Yusuf Qardhawi berasal dari kata al-tatharuf yang berarti "berdiri di ujung, jauh dan pertengahan”. Juga dapat diartikan dengan berlebihan dalam menyikapi sesuatu, seperti berlebihan dalam hal agama, berfikir dan berprilaku. ${ }^{17}$

Sedangkan, Adeed Dawisa sebagaimana dikutip Azyumardi Azra menyatakan bahwa : Istilah radikal mengacu kepada gagasan dan tindakan kelompok yang bergerak untuk menumbangkan tatanan politik mapan; negara-negara atau rejim-rejim yang bertujuan melemahkan otoritas politik dan legitimasi negara-negara dan rejimrejim lain; dan negara-negara yang berusaha menyesuaikan atau mengubah hubungan-hubungan kekuasaan yang ada dalam sistem internasional. Istilah radikalisme karenanya, secara intrinsik berkaitan dengan konsep tentang perubahan politik dan sosial pada berbagai tingkatan. ${ }^{18}$

Belum ada kesepakatan di antara para ahli untuk

menggambarkan gerakan radikal sehingga memunculkan banyak

terminologi. Kalangan akademisi menilai definisi "radikal" belum dipaparkan secara spesifik oleh pemerintah. Sehingga, akhirnya dapat dibedakan antara definisi radikalisme dan sifat kritis. Rektor Universitas Paramadina Prof Firmanzah memandang terminologi radikal masih sangat ambigu. Ini berbeda dengan

\footnotetext{
17 Yusuf Qardhawi, al-Shahwah alIslamiyah bain al-Juhud wa al-Tatharuf, diterjamahkan oleh Hawin Murthado dengan judul, Islam Radikal; Analisis terhadap Radikalisme dalam Ber-Islam, Solo: Era Intermedia, cet 1: 23.

18 Azyumardi Azra. (1996). Pergolakan Politik Islam Dari Fundamentalisme, Modernisme hingga

Postmodernisme, Jakarta: Paramadina, cet 1: 147148.
}

Page | 114 terminologi terorisme yang sudah sangat jelas. "Kalau terminologi terorisme sudah jelas, afiliasi gerakan-gerakan yang dianggap radikal, misal terkait dengan ISIS atau teror bom," ujar Firmanzah dalam diskusi Perspektif Indonesia yang digelar Smart FM dan Populi Center di Jakarta, Sabtu (9/6/2018). Oleh karena itu, ia meminta pemerintah dan instansi terkait memberikan definisi yang lebih terperinci terkait terminologi radikalisme. Sehingga, perguruan tinggi termasuk para rektor dapat membedakan. "Mana yang membahayakan keutuhan NKRI dan itu menjadi perhatian kita bersama, mana yang memang masih dalam kategori sikap kritis," kata Firmanzah. ${ }^{19}$

Dalam pandangan Islam, radikalisme tidak mencerminakan demokrasi dan sangat ditentang. Islam bukanlah agama yang radikal, hal ini dapat kita lihat dalam firman Allah pada surat Al-Baqarah [2]:143

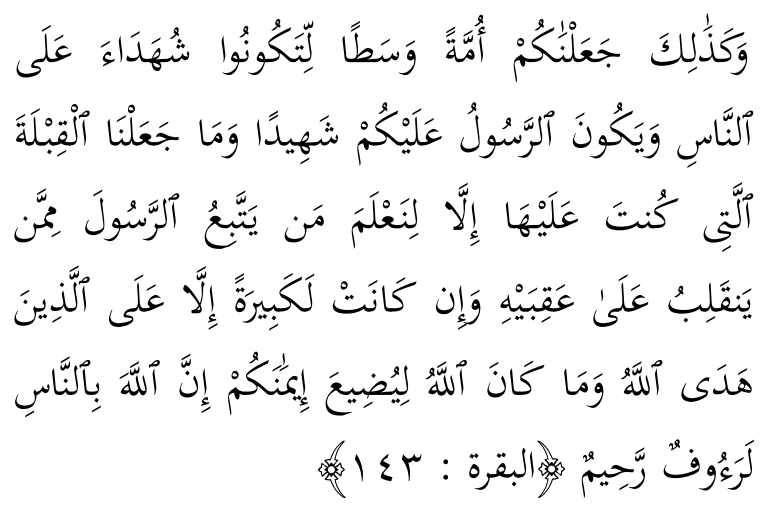

Dan demikian pula Kami telah menjadikan kamu (umat Islam) "umat pertengahan" agar kamu menjadi saksi atas (perbuatan) manusia dan agar Rasul

19 Sakina Rakhma Diah Setiawan. (15 Agustus 2019). Akademisi Minta Pemerintah Perjelas Definisi Radikal sourches URL https://nasional.kompas.com/read/2018/06/09/14491 851/akademisi-minta-pemerintah-perjelas-definisiradikal. 
(Muhammad) menjadi saksi atas (perbuatan) kamu. Kami tidak menjadikan kiblat yang (dahulu) kamu (berkiblat) kepadanya melainkan agar Kami mengetahui siapa yang mengikuti Rasul dan siapa yang berbalik ke belakang. Sungguh, (pemindahan kiblat) itu sangat berat, kecuali bagi orang yang telah diberi petunjuk oleh Allah. Dan Allah tidak akan menyia-nyiakan imanmu. Sungguh, Allah Maha Pengasih, Maha Penyayang kepada manusia. (QS. Al-Baqarah [2]: 143)

\section{Dalam bahasa Arab وَسَطَ}

bermakna الحيار yang berarti umat pilihan. ${ }^{20}$ gَ وَسَرُ membawa keadilan, ${ }^{21}$ umat terbaik. ${ }^{22}$ Menurut Ar-Razy وَسَ' mempunyai empat $\operatorname{arti}^{23}$

1. Sedang dan berbudi luhur

2. Berkeadilan dan moderat

3. Terpuji, banyak kelebihan

4. Pertengahan tidak melampaui batas

Dilihat dari beberapa penafsiran ulama di atas jelas Islam bukanlah termasuk radikal, Islam adalah moderat yang mempunyai budi pekerti yang mulia. Kalau ada yang radikal itu karena tidak menjalankan ajaran Islam secara benar. Bahkan Islam melarang sikap radikal sebagaimana firman Allâh:

${ }^{20}$ Muhammad bi Jarîr bin Yazîz bin Katsîr bin Ghâlib al-Âmiliy Abû Ja'far al-Thabarî, Jâmi' al-Bayân fì ta'wîl al-Qur'ân. (1420 H/ 2000 M). Bairût: Muassasah al-Risâlah. Cet 1.Juz 3: 141.

${ }^{21}$ Jalâl al-Dîin Muhammad ibn Ahmad AlMahallî dan Jalâl al-Dîin Abd al-Rahmân ibn Abî Bakr al-Suyûthî. (t.t). Tafsîr al-Jalâlain, Qâhirah: Dâr al-Hadîts: 27.

${ }^{22}$ Abû al-Fidâ`Ibn Katsir al-Damisqiy. (1417 H/ 1997 M). Tafsîr al-Qur'ân al-'Azhîm, Bairût: Dâr al-Fikr. Cet. 1. Jjuz 1: 214.

23 Ahmad al-Râzî Fakhruddîn Ibn al'Allâmah Dhiyâu al-Dîn 'Umar, Al-Tafsîr Al-Kabîr wa Al-Mafâtîh Al-Ghaib.... Juz 4: 108.

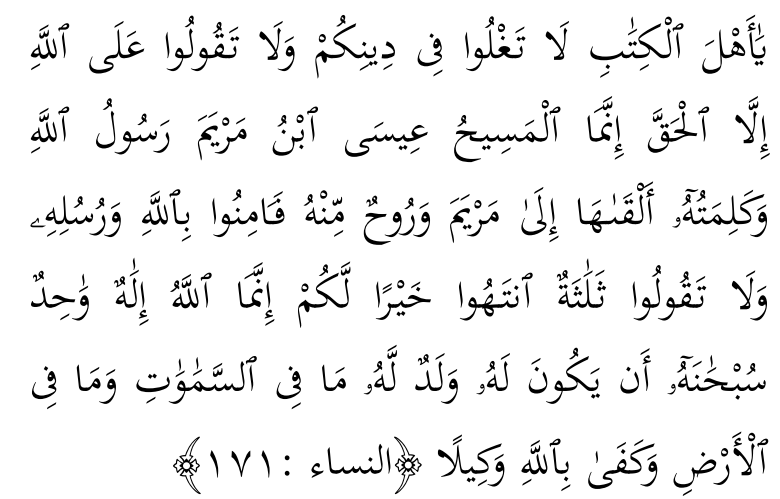

Wahai Ahli Kitab! Janganlah kamu melampaui batas dalam agamamu, dan janganlah kamu mengatakan terhadap Allah kecuali yang benar. Sungguh, AlMasih Isa putra Maryam itu adalah utusan Allah dan (yang diciptakan dengan) kalimat-Nya yang disampaikanNya kepada Maryam, dan (dengan tiupan) roh dari-Nya. Maka berimanlah kepada Allah dan rasul-rasul-Nya dan janganlah kamu mengatakan, "(Tuhan itu) tiga," berhentilah (dari ucapan itu). (Itu) lebih baik bagimu. Sesungguhnya Allah Tuhan Yang Maha Esa, Mahasuci Dia dari (anggapan) mempunyai anak. Milik-Nyalah apa yang ada di langit dan apa yang ada di bumi. Dan cukuplah Allah sebagai pelindung. (QS. AnNisa'[4]:171)

Pada ayat di atas ahli Kitab melampaui batas dalam ucapannya manusia pun (nabi Isa) dianggap sebagai tuhan. ${ }^{24}$ Ini termasuk contoh radikal. Dan Islam melarang ini. Radikalisme tidak mengenal dari mana dia berasal. Dia adalah pemahaman yang melampaui batas kewajaran baik itu di bidang agama, politik, ekonomi, budaya dan lainnya.

\section{Penegakan Hukum}

\footnotetext{
${ }^{24}$ Jalâl al-Dîin Muhammad ibn Ahmad AlMahallî dan Jalâl al-Dîin Abd al-Rahmân ibn Abî Bakr al-Suyûthî, Tafsîr al-Jalâlain, ... : 132.
}

Page | 115 
Penegakan hukum menurut Maroni sebagaimana yang dikutip Carto Nuryanto, merupakan rangkaian proses untuk menerapkan nilai-nilai, ide, dan cita hukum yang bersifat abstrak menjadi tujuan hukum. Tujuan hukum atau cita hukum memuat moral hukum seperti keadilan hukum dan kebenaran. ${ }^{25}$

Penegakan hukum dilakukan dalam masyarakat terbagi kepada dua yaitu, secara makro dan secara mikro. Adapun secara Makro, penegakan hukum meliputi semua aspek kehidupan dalam masyarakat, berbangsa maupun bernegara, untuk melaksankan norma hukum yang ada. Baik itu dalam ruang sempit aspek penal (hukum pidana maupun aspek non-penal (di luar hukum pidana). Sedangkan secara mikro, penegakan hukum ini terbatas pada proses pemeriksaan di pengadilan termasuk proses dilakukannya penyidikan, penuntutan sampai pelaksanaan putusan pengadilan yang telah mempunyai kekuatan hukum tetap. Hakim merupakan salah satu dari penegak hukum yang mempunyai peran sangat penting dalam mewujudkan keadilan melalui putusan-putusannya yang dilakukan oleh hakim. ${ }^{26}$

Pada dasarnya, penegakan hukum bukan hanya semata-mata tugas dari aparat penegak hukum, tetapi menjadi kewajiban seluruh komponen bangsa. Hal ini sebagaimana diamanatkan dalam Pasal 27 ayat (1) Undang-Undang Dasar Negara Republik Indonesia Tahun 1945 yang menegaskan bahwa: "Segala warga bersamaan

25 Carto Nuryanto. (2018). Penegakan Hukum Oleh Hakim Dalam Putusannya Antara Kepastian Hukum Dan Keadilan. dalam Jurnal Hukum Khaira Ummah. 13 (1): $73 .$.

${ }^{26}$ Al-Jawi, Muhammad Nawawi, Syeikh. (tth,. Mirah Labiid Tafsiru an-Nawawi, Dar alKutub Islamiyyah: Jakarta,Juz 1: 194. kedudukannya di dalam hukum dan pemerintahan dan wajib menjunjung hukum dan pemerintahan itu dengan tidak ada kecualinya". Hal ini senada dengan $\mathrm{Al}$-qur'an surat al-Maidah ayat 8:

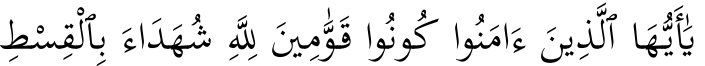

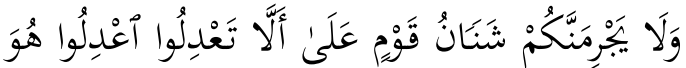

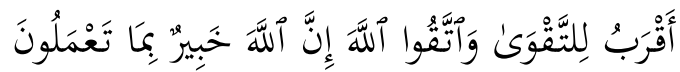

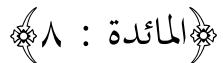

"Wahai orang-orang yang beriman! Jadilah kamu sebagai penegak keadilan karena Allah, (ketika) menjadi saksi dengan adil. Dan janganlah kebencianmu terhadap suatu kaum mendorong kamu untuk berlaku tidak adil. Berlaku adillah. Karena (adil) itu lebih dekat kepada takwa. Dan bertakwalah kepada Allah, sungguh, Allah Mahateliti terhadap apa yang kamu kerjakan". (QS. Al-Maidah/5: 8)

Dari petunjuk redaksi ayat di atas dalam Tafsir Marâh Labîd li Kasyfi Ma'nâ Qur'ânim Majîd karya Syeikh Muhammad Nawawi Al-Bantani, menungkapkan bahwa ada dua beban kerja yang harus dilaksanakan orang yang beriman, yaitu:

1. Mengagungkan perintah Allah, yaitu

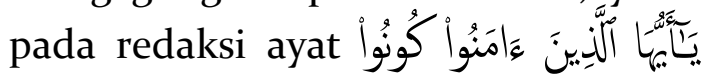
قَوََمِينَ لمِنَِّ Wahai orang-orang yang beriman! Jadilah kamu sebagai penegak keadilan karena Allah, beban kerja bagi seorang yang beriman disini adalah mampu melaksanakan tugas perintah secara benar dengan penuh ketaatan kepada Allah dan menjauhi berbagai larangan-Nya.

2. Mempunyai rasa simpati dan empati terhadap makhluk yang Allah ciptakan, yaitu pada redaksi ayat

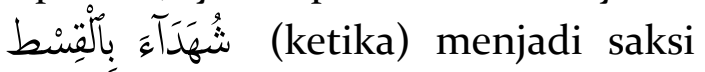
bersaksilah dengan adil, saksi harus 
memberikan keterangan sesuai dengan fakta tidak menyalahi kenyataan dan bukti yang terjadi

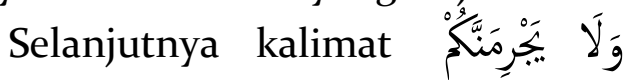

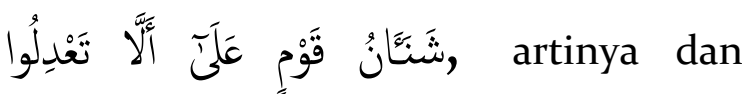
janganlah kebencianmu terhadap suatu kaum mendorong kamu untuk berlaku tidak adil, Syaikh Nawani dalam tafsirnya memberikan penjelasan اى لا يحملنكم بعض قوم على ان تجوروا عليهم وتجاوجوا

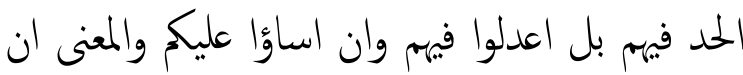

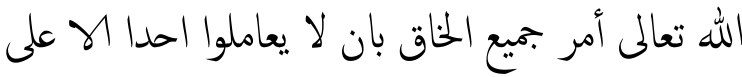
artinya jangan karena kebencian terhadap sebagian pihak lalu memberikan putusan yang menyimpang kepada mereka dan memberikan hukuman yang melampai batas terhadap sebagian pihak tersebut, akan tetapi berbuat adilllah terhadap mereka walaupun mereka berbuat tidak baik terhadap kamu sebelumnya dengan artian bahwasanya Allah memerintahkan kepada semuanya untuk memutuskan secara adil dan meninggalakan putusan yang lalim. ${ }^{27}$

Sedangkan menurut syaikhMuhammad 'Alî al-Shâbunî dalam tafsir Shafwah al-Tafâsîr, لا يحملنك شدة غضكم للأعداء على ترك العدل فيهم والاعتداء عليهم jangan karena terlalu benci terhadap lawan sehingga meninggalkan berbuat adil pada mereka dan melakukan tindakan yang agresif terhadap mereka. ${ }^{28}$

Adapun teks ayat sesudahnya adalah

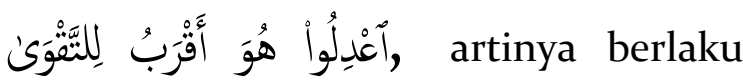

27 Al-Jawi, Muhammad Nawawi.. (tth). Mirah Labiid Tafsiru an-Nawawi ......: 194.

${ }^{28}$ Al-Shabuni, Muhammad 'Ali. (tth). alShafwah al-Tafasir, Beiru : Dar al-Kutub alIslamiyyah, Jilid 1: 330. adillah. Karena (adil) itu lebih dekat kepada takwa. Berbuat adil itu tidak melihat kepada lawan atau kawan. Orang yang berbuat adil ini akan terhindar dari kedurhakaan kepada Allah dan terhindar dari azab Allah. Sebagai akhir atau ujung ayat tersebut

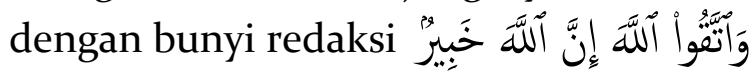
بَِِا تَعْمَلُونَ Dan bertakwalah kepada Allah, sungguh, Allah Maha Teliti terhadap apa yang kamu kerjakan. Semua hal yang dilakukan tidak ada yang tersembunyi bagi Allah, Allah akan menampakkan perbuatan yang dilakukan dan memberikan balasannya. ${ }^{29}$

Nabi Muhammad membagi hakim kepada tiga bagian sebagaimana sabda Rasul:

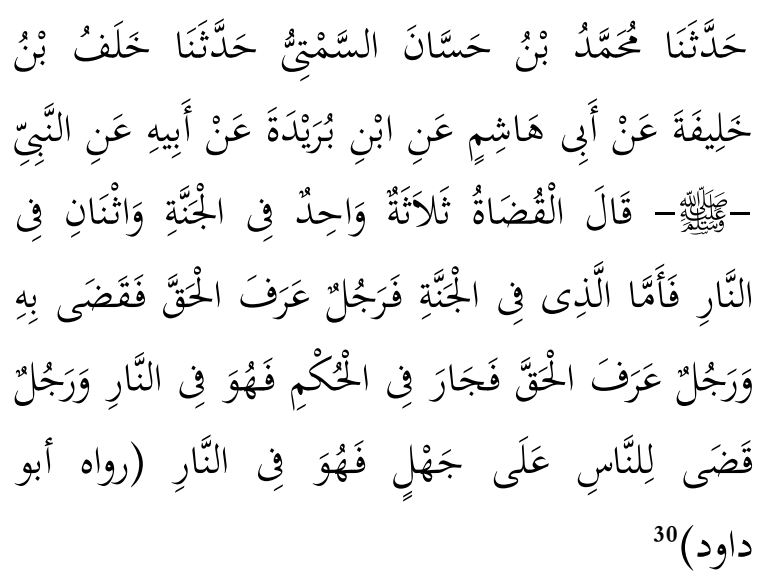
... Dari Ibn Buraidah dari ayahnya, dari Nabi 留稫 bersabda hakim itu ada tiga golongan, satu golongan masuk surga sedangkan dua golongan yang lainnya msuk neraka. Adapun golongan yang masuk surga adalah hakim yang mengetahui hukum yang sebenarnya menurut hukum Allah dan dia menghukum dengan hak itu. Sedangkan

29 Al-Jawi, Muhammad Nawawi. (tth). Mirah Labiid Tafsiru an-Nawawi...: 194.

${ }^{30}$ Abû Dâwûd Sulaimân Ibn al-Asy'ats AlSajastâniy. (t.t). Sunan Abî Dâwûd, Bairût: Dâr alKitâb al-'Arabiy. Juz 3, No. 3575. Bab fî al-Qâdhî Yakhtha'u.: 324 
hakim yang mengetahui hukum yang sebenarnya menurut hukum Allah tapi dia menyelewengkan hukum itu maka hakim tersebut golongan yang masuk neraka dan hakim yang menghukum manusia tanpa ilmu pengetahuan maka diapun termasuk golongan hakim yang masuk neraka. (HR. Abu Daud)

Dalam Islam seleksi untuk hakim sangat ketat, menurut imam Taqiyu aldîn harus memenuhi syarat di bawah ini: $:^{31}$

1. Islam

2. Baligh

3. Berakal

4. Merdeka

5. Adil

6. Laki-laki

7. Mengerti al-Qur'an

8. Mengerti Hadits

9. Mengetahui Ijma' ulama dan perselisihan paham mereka

10. Mengerti tetang Qiyas

11. Mengetahui bahasa Arab

12. Pendengaran bagus

13. Penglihatan bagus

14. Sadar

15. Memunyai kecakapan dalam berkomunikasi

Selaian syarat di atas seorang hakim harus mempunyai etika, karena kedudukan hakim adalah kedudukan yang mulia, diantaranya adalah: ${ }^{32}$

1. Berkantor di tengah negeri

2. Dapat dijumpai masyarakat dengan mudah

\footnotetext{
${ }^{31}$ Taqiyu al-Dîn Abî Bakrin Muhammad alHusainiy al-Hushniy al-Damasyqiy al-Syâfi'iy. (1422 H/2001 M). Kifâyatu al-Akhyâr fî̀ halli Ghâyati al-Ikhtishâr. Bairut: Dâr al-Kutubu al'Ilmiyyah: 727-729.

${ }^{32}$ Taqiyu al-Dîn Abî Bakrin Muhammad al-

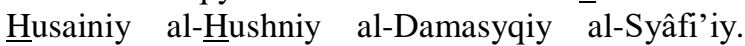
(1422 H/2001 M). Kifâyatu al-Akhyâr fî halli Ghâyati al-Ikhtishâr. ...: 729-737.
}

3. Tidak boleh memutuskan perkara di masjid

4. Hakim harus menyamakan pada dua orang berperkara dalam hal tempat mereka, berbicara dan perkataan manis tidaknya.

5. Tidak boleh menerima pemberian dari rakyatnya

6. Jangan memutuskan perkara ketika dalam keadaan ; marah, lapar, haus, larut malam, sangat susah, sangat gembira, ketika sakit, kebelet buag hajat, mengantuk dan cuaca ekstrim panas atau dingin.

7. Memberikan kesempatan untuk pemohon memberikan keterangan sampai selesai setelah itu memberikan kesempatan pula bagi terdakwa menyampaikan keterangannya,

8. Hakim tidak boleh menyuruh sumpah atas terdakwa tanpa kemauan atau keinginan dan persetujuan dari pemohon

9. Hakim tidak boleh menunjukkan cara mendakwa dan membela kepada keduanya

10. Hakim tidak boleh menrima saksi yang tidak adil

11. Hakim tidak boleh menerima saksi musuh kepada musuhnya

12. Hakim tidak boleh menerima saksi ayah kepada anaknya atau sebaliknya

13. Surat-surat hakim kepada hakim yang lain berisi hukum harus disaksikan dua rang saksi dan mereka berdua mengetahui isi surat itu

\section{Kesimpulan}

Adanya perbedaan pendapat para tokoh Islam dalam menyikapi demokrasi dalam sistem pemerintahan, ada sikap penolakan sama sekali terhadap sistem demokrasi, tapi ada juga demokrasi asalkan sesuai dengan aturan yang ada 
dalam al-Qur'an. Dalam kajian demokrasi yang berwawasan Al-Qur'an maka adanya ayat yang menganjurkan demokrasi pada surat Ali Imran ayat 159. Ayat tesebut menggambarkan bagaimana masalah urusan diselesaikan dengan jan musyawarah. Adapun format dan teknis musyawarah sesuai dengan kebijakan umat sesuai kondisi, tempat dan masa. Kesepakatan musyawarah tersebut adalah kesepakan yang baik, tidak melanggar aturan agama,tidak boleh melakukan kesepakatan yang buruk, sebagaimana firman Allah dalam Al-Qur'an surat Al-Maidah ayat 2. Begitu pula bahwa penegakan hukum ada aturan yang ditetapkan dalam AlQur'an. Hal ini tergambar pada surat alMaidah ayat 8, yang memerintahkan agar seorang yang beriman harus mengagungkan perntah Allah, agar benar-benar menjadi penegak keadilan, jangan karena rasa kebencian, maka tidak berlaku adil. Dengan adanya ayat yang menganjurkan demokrasi dan penegakan hukum. Maka Islam tidak bisa dipisahkan dengan masalahmasalah keduniawian khususnya pada demokrasi dan penegakan hukum. Dengan demikian pendapat sekuler tidak sesuai dengan Al-Qur'an atau pandangan agama Islam.

\section{References}

Departemen Agama RI. (1425 H/2004). Al-Qur'an dan Terjemah, Surabaya: CV. Mekar.

Abû al-Fidâ' Ibn Katsir al-Damisqiy. (1417 H/ 1997 M). Tafsîr al-Qur'ân al'Azhîm, Bairût: Dâr al-Fikr. Cet. 1. Jjuz 1: 214.

Abû Dâwûd Sulaimân Ibn al-Asy'ats AlSajastâniy. (t.t). Sunan Abî Dâwûd, Bairût: Dâr al-Kitâb al'Arabiy. Juz 3, No. 3575. Bab fí alQâdhî Yakhtha'u.: 324.
Afifa Rangkuti (2018). Demokrasi dalam Pandangan Islam dan Barat, dalam Jurnal Ilmiah Penegakan Hukum, 5 (2): 49-59.

Ahmad al-Râzî Fakhruddîn Ibn al'Allâmah Dhiyâu al-Dîn 'Umar, Al-Tafsîr Al-Kabîr wa Al-Mafâtîh Al-Ghaib.... Juz 4: 108.

Al-Jawi, Muhammad Nawawi, Syeikh. (tth,. Mirah Labiid Tafsiru anNawawi, Dar al-Kutub Islamiyyah: Jakarta,Juz 1: 194.

Al-Maududiy, Abu al-A'la. (1977). Mabdi'u al-Islam. Damaskus: Dar al-Qur'an al-Karim: 130.

Al-Shabuni, Muhammad 'Ali. (tth). alShafwah al-Tafasir, Beiru : Dar al-Kutub al-Islamiyyah, Jilid 1: 330.

Azyumardi Azra. (1996). Pergolakan Politik Islam Dari Fundamentalisme, Modernisme hingga

Postmodernisme, Jakarta: Paramadina, cet 1: 147-148.

Carto Nuryanto. (2018). Penegakan Hukum Oleh Hakim Dalam Putusannya Antara Kepastian Hukum Dan Keadilan. dalam Jurnal Hukum Khaira Ummah. 13 (1): 73 .

Eva Iryani Hukum Islam. (2017). Demokrasi dan Hak Asasi Manusia dalam Jurnal Ilmiah Universitas Batanghari Jambi. 17 (2): 24-31.

Farida Nur 'Afifah (2020). Demokrasi dalam Al-Qur'an:Implementasi Demokrasi di Indonesia dalam Jurnal Kaca Jurusan Ushuluddin STAI AL FITHRAH. 10 (1): 6-32. 
Fazlur Rahman (1405/1985). Islam dan Modrenitas. Bandung: Pustaka: 54 .

Harun Nasution. (1975). Pembaharuan Dalam Islam Sejarah Pemikiran Dan Gerakan. Jakrta: Bulan Bintang: 131.

Ilyas Bayunus dan Farit Ahmad. (1996). Sosiologi Islam Dan Masyarakat Kontemporer. Bandung: Mizan: 54.

Irfan Idris.(15 Agustus 2019). Ini Kriteria Radikalisme Menurut BNPT sourches URL https://www.republika.co.id/beri ta/nasional/umum/15/03/31/nm2 pur-ini-kriteria-radikalismemenurut-bnpt.

Jalâl al-Dîin Muhammad ibn Ahmad AlMahallî dan Jalâl al-Dîin Abd alRahmân ibn Abî Bakr al-Suyûthî. (t.t). Tafsîr al-Jalâlain, Qâhirah: Dâr al-Hadîts: 27.

M. Rais Ahmad (2013). Penegakan Hukum atas Keadilan dalam Pandangan Islam dalam Jurnal Mizan; Jurnal Ilmu Syariah, FAI Universitas Ibn Khaldun (UIKA) BOGOR. 1 (2): 143-148.

Muhammad 'Alî al-Shâbûnî (1420 H/ 1999 M). Shafwah al-Tafâsîr, Jakarta: Dâr al-Kutub alIslâmiyah, cet 1, jilid 1: 240 .

Muhammad bi Jarîr bin Yazîz bin Katsîr bin Ghâlib al-Âmiliy Abû Ja'far al-Thabarî, Jâmi' al-Bayân fî ta'wîl al-Qur'ân. (1420 H/ 2000 M). Bairût: Muassasah al-Risâlah. Cet 1.Juz 3: 141.

Sakina Rakhma Diah Setiawan. (15 Agustus 2019). Akademisi Minta Pemerintah Perjelas Definisi Radikal sourches URL https://nasional.kompas.com/read /2018/o6/og/14491851/akademisi- minta-pemerintah-perjelasdefinisi-radikal.

Sukron Kami (2013) Pemikiran Poiitik Islam Tematik, Jakarta: Kencana Prenada Media Grouop, cet 1: 85 .

Sulaiman Rasjid, H.(2005). Fiqh Islam, Bandung: Sinar Baru Algensindo, cet 37: 504.

Taqiyu al-Dîn Abî Bakrin Muhammad al-nusainiy al-nushniy alDamasyqiy al-Syâfi'iy. (1422 H/2001 M). Kifâyatu al-Akhyâr fi halli Ghâyati al-Ikhtishâr. Bairut: Dâr al-Kutubu al-'Ilmiyyah: 727729 .

Tim Penyusun Kamus Departemen Pendidikan dan Kebudayaan. (2008). Kamus Besar Bahasa Indonesia, Jakarta: Balai Pustaka, .cet. 16: 1151-1152.

Yusuf Qardhawi, al-Shahwah alIslamiyah bain al-Juhud wa alTatharuf, diterjamahkan oleh Hawin Murthado dengan judul, Islam Radikal; Analisis terhadap Radikalisme dalam Ber-Islam, Solo: Era Intermedia, cet 1: 23. 